УДК 546.561

\title{
ПАРАМЕТРЫ АКТИВНОСТИ НАНОПОРОШКОВ МЕДИ ПРИ ДЛИТЕЛЬНОМ ХРАНЕНИИ В УСЛОВНО-ГЕРМЕТИЧНОЙ ТАРЕ
}

\author{
Тихонов Дмитрий Владимирович', \\ dv11@mail.ru \\ Ильин Александр Петрович', \\ ilyin@tpu.ru \\ Беспалова Екатерина Александровна, \\ katena.bespalova9570@gmail.com \\ Национальный исследовательский Томский политехнический университет, \\ Россия, 634050, г. Томск, пр. Ленина, 30. \\ 2 Бийский технологический институт, \\ 659305, Россия, г. Бийск, ул. им. Героя Советского Союза Трофимова, 27.
}

\begin{abstract}
Актуальность исследования связана с определением параметров активности серии нанопорошков меди после хранения в течение 16 лет в условно-герметичной таре и на их основе получением данных о деградации меди в нанодисперсном состоянии. Цель: экспериментально определить четыре параметра химической активности серии нанопорошков меди и установить закономерности изменения этих параметров после длительного хранения этих нанопорошков в условно-герметичной таре.

Объект: нанопорошки меди, синтезированные в условиях электрического взрыва проводника в среде аргона.

Методы. Фазовый состав серии нанопорошков меди определяли с использованием дифрактометра «Shimadzu» XRD-700. Paзмеры и форму частиц анализировали с помощью растрового электронного микроскопа JSM-7500FA «Jеo/». Площадь удельной поверхности нанопорошков меди измеряли с помощью метода низкотемпературной адсорбции азота (метод БЭТ). Содержание металлической меди определяли с использованием термогравиметрии при нагревании до $1020{ }^{\circ} \mathrm{C}$ со скоростью 10 \% мин. Реакционную способность нанопорошков меди определяли по четырем параметрам активности: температура начала окисления $\left(t_{\text {so, }}{ }^{\circ} \mathrm{C}\right)$, максимальная скорость окисления $\left(V_{\text {max }}\right.$ мг/мин), степень окисленности $(\alpha, \%)$ и энтальпия окисления $\Delta H$, кДж/моль. Для расчета этих параметров использовали дериватограф Q-1000 (фирма MOM) и термоанализатор Q600 STD (фирма TA-Instrument).

Результаты. После хранения (16 лет) нанопорошков меди в условно-герметичной таре часть образцов стали пирофорными: их температура окисления понизилась до 19 и $16^{\circ} \mathrm{C}$. В то же время имеются образцы с температурой начала окисления 188 и $190{ }^{\circ} \mathrm{C}$. Максимальная скорость окисления нанопорошков меди составляла $32,3 \cdot 10^{-4} \mathrm{Mr} / \mathrm{C}$, а минимальная только 5,2·10-4 $\mathrm{Mr} / \mathrm{c}$. При нагревании до $650{ }^{\circ} \mathrm{C}$ энтальпия окисления нанопорошков меди для подавляющей части образцов составляла $\approx 1500$ Дж/г. Содержание металлической меди в нанопорошках образцов составляло от 46,7 до 73,5 мас. \%. Отсутствие корреляционных зависимостей между условиями электрического взрыва и параметрами активности связано, по-видимому, с многопараметрической зависимостью формирования оксидной оболочки на частицах меди: значимыми являются условия пассивирования. Особенностью нанопорошков меди является невозможность формирования защитной плёнки на поверхности частиц: продуктами окисления является кристаллическая фаза СиО и рентгеноаморфный оксид $\mathrm{Cu}_{2} \mathrm{O}$ в виде кластеров с характерными размерами 4-6 нм.
\end{abstract}

\section{Ключевые слова:}

Нанопорошок, медь, электрический взрыв, параметры активности, термический эффект,

температура начала окисления, хранение, воздух, максимальная скорость окисления, энтальпия окисления.

\section{Введение}

Медь относится к металлам с низкой активностью и в ряду напряжений находится после водорода [1]. Общепризнано, что вещества в наносостоянии имеют новые свойства [2], но в конкретных случаях новые свойства многими учёными отрицаются [3-5].

Одной из основных проблем практического применения нанопорошков меди является сохранение высокого содержания металлической меди и её реакционной способности. Вместе с тем для получения устойчивого нанопорошка меди необходимо после его получения частично окислить и тем самым снизить содержание меди до 95-96 мас. \% [2].

Любые нанопорошки являются нестабильными или метастабильными системами «твердое тело - газ». В сравнении с веществами с низкой дисперсностью нанопорошки металлов имеют высокую реакционную способность [6] и взаимодействуют с окружающей средой $[7,8]$. Основным окислителем нанопорошков (НП) металлов являются протоны, которые образуются при диссоциации молекул воды на поверхности наночастиц [9]. Особенностью структуры наночастиц (НЧ) металлов [8, 9], сформированной при пассивировании в воздухе, является наличие двойного электрического слоя (ДЭС): адсорбированные молекулы воды диссоциируют на протоны, которые диффундируют в объем наночастицы, и гидроксид-ионы, которые стабилизируются на поверхности. Последние химически связываются поверхностью НЧ, а протоны окисляют металл, образуя атомы и затем молекулы водорода [10]. Для ряда металлов (алюминий, титан, цирко- 
ний и гафний) протоны образуют соответствующие гидриды [10]. При уменьшении диаметра частиц металлов состояние атомов сначала на поверхности, а с диаметра 10-30 нм и в объёме частиц изменяется и переходит в нестабильное состояние [10]. Формирование и природа защитных плёнок на поверхности частиц меди зависит от их диаметра (кривизны поверхности). При уменьшении диаметра до 1 мкм сохраняется диффузионный механизм формирования защитной плёнки, толщина которой составляет 20-40 мкм [11]. Для частиц меди диаметром менее 100 нм в связи с изменением состояния атомов на поверхности структура и состав защитной плёнки также изменяется. Процесс окисления меди в наносостоянии тормозится при формировании двойного электрического слоя, обладающего псевдоёмкостью, с внутренним положительно заряженным слоем. Устойчивость двойного слоя определяет устойчивость нанопорошков меди при хранении. Косвенным подтверждением наличия двойного электрического слоя является тонкий защитный слой 2-10 нм, который не может быть сформирован по диффузионному механизму [8]. Кроме того, с уменьшением диаметра наночастиц меди толщина двойного электрического слоя снижается. При нагревании происходит разрушение двойного электрического слоя, окисление нанопорошка меди и наблюдается пороговое явление, связанное с экстремальным тепловыделением [12].

\section{Описание объекта исследования и методик эксперимента}

Нанопорошки меди (НПМ) получали с помощью экспериментальной установки $[2,13]$, оснащенной механизмом автоматической подачи проводника при частоте следования электровзрывов 0,6 Гц. Принципиальная схема установки приведена на рис. 1. В качестве взрываемого проводника использовали проволоку диаметром 0,35 мм с содержанием меди 99,8 мас. \%. В ходе проведения эксперимента зарядная емкость накопителя энергии составляла 2,02 мкФ, а длина взрываемых проводников не изменялась и составляла 80 мм.

В качестве рабочего газа применяли аргон при давлении $1,52 \cdot 10^{5}$ Па. Взрывы проводников проводили в режиме «быстрого взрыва» (по классификации Беннета) [13]. Величину удельной введенной энергии $\left(W / W_{c}\right)$ и удельной энергии дуговой стадии $\left(W_{\text {д }} / W_{\text {с }}\right)$ регулировали путем изменения зарядного напряжения $\left(U_{0}\right),(W-$ энергия, введенная в проводник на стадии собственно взрыва, $W_{\text {д }}$ энергия, введенная в проводник на стадии дугового разряда, $W_{\text {с }}$ - энергия сублимации взрываемого проводника). Энергию, введенную в проводник, рассчитывали по данным осциллограмм тока $[14,15]$. Изучали порошок, осевший в сборнике нанопорошка (рис. 1, поз. 12) и прошедший пассивирование в среде аргона с контролируемым напуском воздуха.

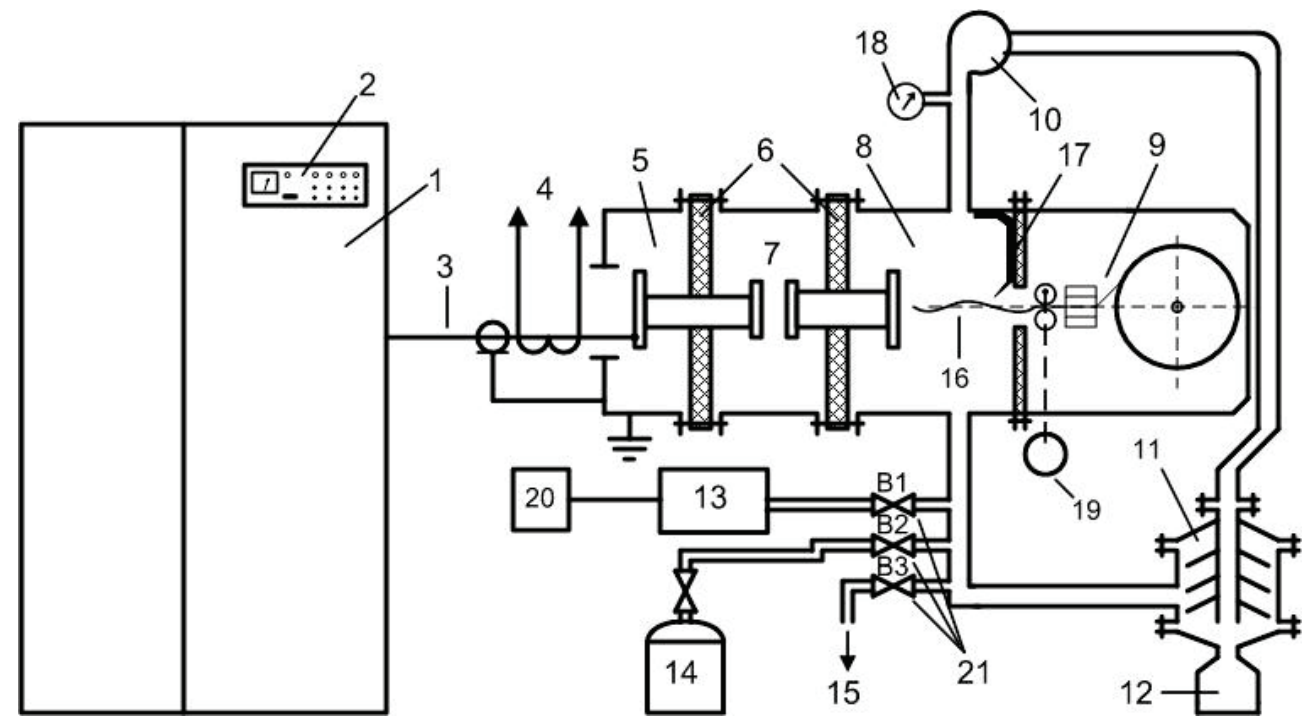

Рис 1. Принципиальная схела установки: 1 - блок питания установки; 2 - пульт управления; 3 - высоковольтные кабели; 4 - токовый шунт; 5 - калера высоковольтного ввода; 6 - проходные изоляторы; 7 - разрядник; 8 - взрывная калера; 9 - механизм подачи проводника; 10 - вентилятор; 11 - фильтр-уловитель нанопорошка; 12 - сборник нанопорошка; 13 - форвакуулный насос; 14 - баллон с газом; 15 - трубопровод для сброса газа в вытяжную вентиляиию; 16 - взрывающийся проводник; 17 - заземленный электрод; 18 - мановакуулетр; 19 - двигатель механизла подачи проводника; 20 - пульт управления форвакуулныл насосом; 21 - газовые краны

Fig. 1. Scheme of installation: 1 is the power supply unit; 2 is the control panel; 3 are the high-voltage cables; 4 is the current shunt; 5 is the highvoltage input chamber; 6 are the feedthrough insulators; 7 is the spark-gap; 8 is the explosion chamber; 9 is the mechanism of wire feeding; 10 is the ventilator of gas circulation; 11 is the collection filter for nanopowders; 12 is the collector of nanopowders; 13 is the forevacuum pump; 14 is the gas-cylinder; 15 is the gas discharge line; 16 is the exploding wire; 17 is the grounded electrode; 18 is the manovacuum meter; 19 is the electric motor of mechanism of wire feeding; 20 is the control panel of forvacuum pump; 21are the gas ball valves 
Таблииа 1. Параметры синтеза нанопорошков меди в условиях әлектрического взрыва

Table 1. Parameters of the copper nanopowders synthesis under electric explosion conditions

\begin{tabular}{|c|c|c|c|c|c|}
\hline $\begin{array}{l}\text { Обозначение } \\
\text { образца } \\
\text { Sample name }\end{array}$ & $U_{0},{ }_{\mathrm{K}} \mathrm{B}(\mathrm{kV})$ & $W$, Дж (J) & $W_{\text {д }}$, Дж (J) & $W / W_{\mathrm{s}}$ & $W_{\text {д }} / W_{\mathrm{s}}$ \\
\hline $\mathrm{Cu}-30$ & 30 & 548 & 182 & 2,12 & 0,70 \\
\hline $\mathrm{Cu}-28$ & 28 & 500 & 134 & 1,93 & 0,52 \\
\hline $\mathrm{Cu}-26$ & 26 & 453 & 90 & 1,74 & 0,34 \\
\hline $\mathrm{Cu}-24$ & 24 & 404 & 63 & 1,56 & 0,24 \\
\hline $\mathrm{Cu}-22$ & 22 & 366 & 18 & 1,41 & 0,07 \\
\hline $\mathrm{Cu}-20$ & 20 & 319 & 0 & 1,23 & 0 \\
\hline $\mathrm{Cu}-18$ & 18 & 232 & 0 & 0,89 & 0 \\
\hline
\end{tabular}

Фазовый состав нанопорошков определяли с использованием рентгеновского дифрактометра «Shimadzu» XRD-7000 (излучение $\mathrm{Cu}_{\text {к } \alpha}$ ). Размер и форму частиц анализировали с помощью растрового микроскопа JSM-7500FA «Jeol». Площадь удельной поверхности $\left(S_{\text {уд }}\right)$ нанопорошка измеряли с помощью метода низкотемпературной адсорбции азота (метод БЭТ). Реакционную способность НПМ определяли по четырем параметрам химической активности [16, 17]: температуре начала окисления, максимальной скорости окисления, степени окисленности НПМ и энтальпии окисления. Для расчета этих параметров, а также для расчета содержания металлической меди в НПМ использовали термограммы, полученные с помощью дериватографа Q-1000 и термоанализатора Q600 STD при нагревании образцов в воздухе до $1020{ }^{\circ} \mathrm{C}$. [18].

\section{Результаты экспериментов и их обсуждение}

После получения НПМ в условиях ЭВП (табл. 1) нанопорошки пассивировали в отдельном боксе малыми добавками воздуха. При этом температуру НПМ контролировали, и она не превышала $40{ }^{\circ} \mathrm{C}$. Пассивированные НПМ нагревали в ячейке термоанализатора. Результаты ДТА приведены в табл. 2.

таблица 2. Паралетры активности электровзрывных нанопорошков меди после 20 дней хранения

Table 2. Activity parameters of electroexplosive copper nanopowders after 20 days of storage

\begin{tabular}{|c|c|c|c|c|}
\hline $\begin{array}{c}\text { Обозна- } \\
\text { чение } \\
\text { образца } \\
\text { Sample } \\
\text { name }\end{array}$ & $\begin{array}{c}\text { Площадь } \\
\text { удельной } \\
\text { поверхно- } \\
\text { сти, } \mathrm{m}^{2} / \Gamma \\
\text { Specific } \\
\text { surface } \\
\text { area, }^{2} / \mathrm{g}\end{array}$ & $\begin{array}{l}\text { Температура } \\
\text { начала оки- } \\
\text { сления, } t_{\text {н.o }},{ }^{\circ} \mathrm{C} \\
\text { Oxidation on- } \\
\text { set temperatu- } \\
\text { re, } t_{0.0},{ }^{\circ} \mathrm{C}\end{array}$ & $\begin{array}{c}\text { Прирост } \\
\text { массы по } \\
\text { TГ, мaс. \% } \\
\text { (до } 800{ }^{\circ} \mathrm{C} \text { ) } \\
\text { TG mass } \\
\text { gain, wt. \% } \\
\text { (to } 800^{\circ} \mathrm{C} \text { ) }\end{array}$ & $\begin{array}{l}\text { Приведенный } \\
\text { тепловой эффект } \\
(S / \Delta m) \text {, отн. ед. } \\
\text { Reduced thermal } \\
\text { effect, }(S / \Delta m) \text {, } \\
\text { relative units }\end{array}$ \\
\hline $\mathrm{Cu}-30$ & $6,2 \pm 0,2$ & 165 & 20,1 & 1,5 \\
\hline $\mathrm{Cu}-28$ & $8,2 \pm 0,2$ & 170 & 19,4 & 1,4 \\
\hline $\mathrm{Cu}-26$ & $10,2 \pm 0,3$ & 170 & 19,6 & 1,6 \\
\hline $\mathrm{Cu}-24$ & $5,7 \pm 0,2$ & 160 & 18,7 & 1,5 \\
\hline $\mathrm{Cu}-22$ & $3,8 \pm 0,2$ & 170 & 19,8 & 1,5 \\
\hline $\mathrm{Cu}-20$ & $3,7 \pm 0,3$ & 170 & 20,8 & 1,4 \\
\hline $\mathrm{Cu}-18$ & $3,9 \pm 0,1$ & 170 & 20,6 & 1,2 \\
\hline
\end{tabular}

Согласно данным табл. 2 , с увеличением напряжения, подаваемого на проводник, с 18 до $30 \mathrm{kB}$ дисперсность $\left(S_{\text {уд }}\right)$ возрастала и проходила через максимум 10,2 $0,3 \mathrm{~m}^{2} /$ г при напряжении 26 кВ. Дальнейшее увеличение напряжения более 28 кВ приводило к уменьшению $S_{\text {уд }}$. Несмотря на различную дисперсность, $S_{\text {уд }}$ изменялась от 3,7 до $10,2 \mathrm{~m}^{2} / г$, температура начала окисления оставалась практически постоянной $\left(160-170{ }^{\circ} \mathrm{C}\right)$. При нагревании до $800{ }^{\circ} \mathrm{C}$ в среде аргона максимальная скорость окисления меди изменяется не значительно ( 11\%), но определённой зависимости от напряжения, приложенного к проводнику, не наблюдалось. Энтальпия окисления также изменялась без определенной зависимости от условий электрического взрыва (табл. 2).

Таблица 3. Параметры активности электровзрывных нанопорошков меди после 16 лет хранения

Table 3. Activity parameters of electroexplosive copper nanopowders after 16 years of storage

\begin{tabular}{|c|c|c|c|c|c|}
\hline 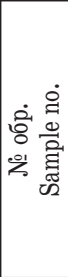 & 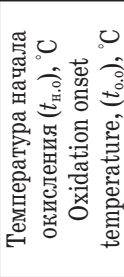 & 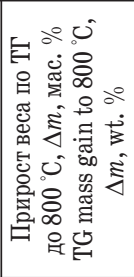 & 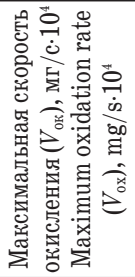 & 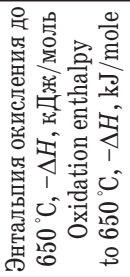 & 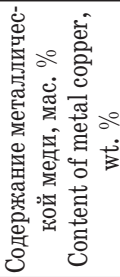 \\
\hline $\mathrm{Cu}-30$ & 38 & 16,40 & 6,32 & 98,3 & 65,7 \\
\hline $\mathrm{Cu}-28$ & 190 & 7,03 & 32,31 & 95,9 & 47,0 \\
\hline $\mathrm{Cu}-26$ & 16 & 12,40 & 12,23 & 99,9 & 50,7 \\
\hline $\mathrm{Cu}-24$ & 158 & 11,41 & 5,21 & 81,5 & 46,7 \\
\hline $\mathrm{Cu}-22$ & 19 & 14,33 & 8,45 & 96,3 & 58,1 \\
\hline $\mathrm{Cu}-20$ & 172 & 16,09 & 26,37 & 95,4 & 64,2 \\
\hline $\mathrm{Cu}-18$ & 188 & 18,39 & 11,64 & 97,3 & 73,5 \\
\hline
\end{tabular}

В табл. 3 приведены параметры активности образцов меди после 16 лет хранения, рассчитанные путем обработки термограмм, полученных с помощью современного оборудования. Порошки меди, даже грубодисперсные, отличаются неустойчивостью при нагревании в воздухе, хотя медь относится к малоактивным металлам [1]. В отличие от нанопорошков алюминия, также хранившихся 16 лет в условно герметичной таре, температура начала окисления которых практически не изменилась, образцы НПМ имеют крайне низкую температуру начала окисления (табл. 3): $\mathrm{Cu}-22\left(19{ }^{\circ} \mathrm{C}\right)$ и $\mathrm{Cu}-26\left(16{ }^{\circ} \mathrm{C}\right)$, т. е. они стали пирофорными после хранения.

В практике хранения нанопорошков меди наблюдалось самопроизвольное их спекание с выделением тепла. Определенной закономерности в изменении температуры начала окисления нанопорошков меди от величины приложенного напряжения, энергии взрыва и энергии дуговой стадии не наблюдается. Фазовый состав образцов НПМ, хранившихся в течении 16 лет, приведён в табл. 4 .

Согласно РФА, фазовый состав образцов НПМ представлен кристаллическими фазами: металлической медью и $\mathrm{CuO}$ (табл. 4). На меди в массивном состоянии в воздухе формируется защитная пленка [1]:

$$
\begin{gathered}
2 \mathrm{Cu}^{0}+\mathrm{O}_{2}+2 \mathrm{H}_{2} \mathrm{O} \rightarrow 2 \mathrm{Cu}(\mathrm{OH})_{2} \downarrow \\
\mathrm{Cu}(\mathrm{OH})_{2}+\mathrm{Cu}^{0} \rightarrow \mathrm{Cu}_{2} \mathrm{O}+\mathrm{H}_{2} \mathrm{O} .
\end{gathered}
$$




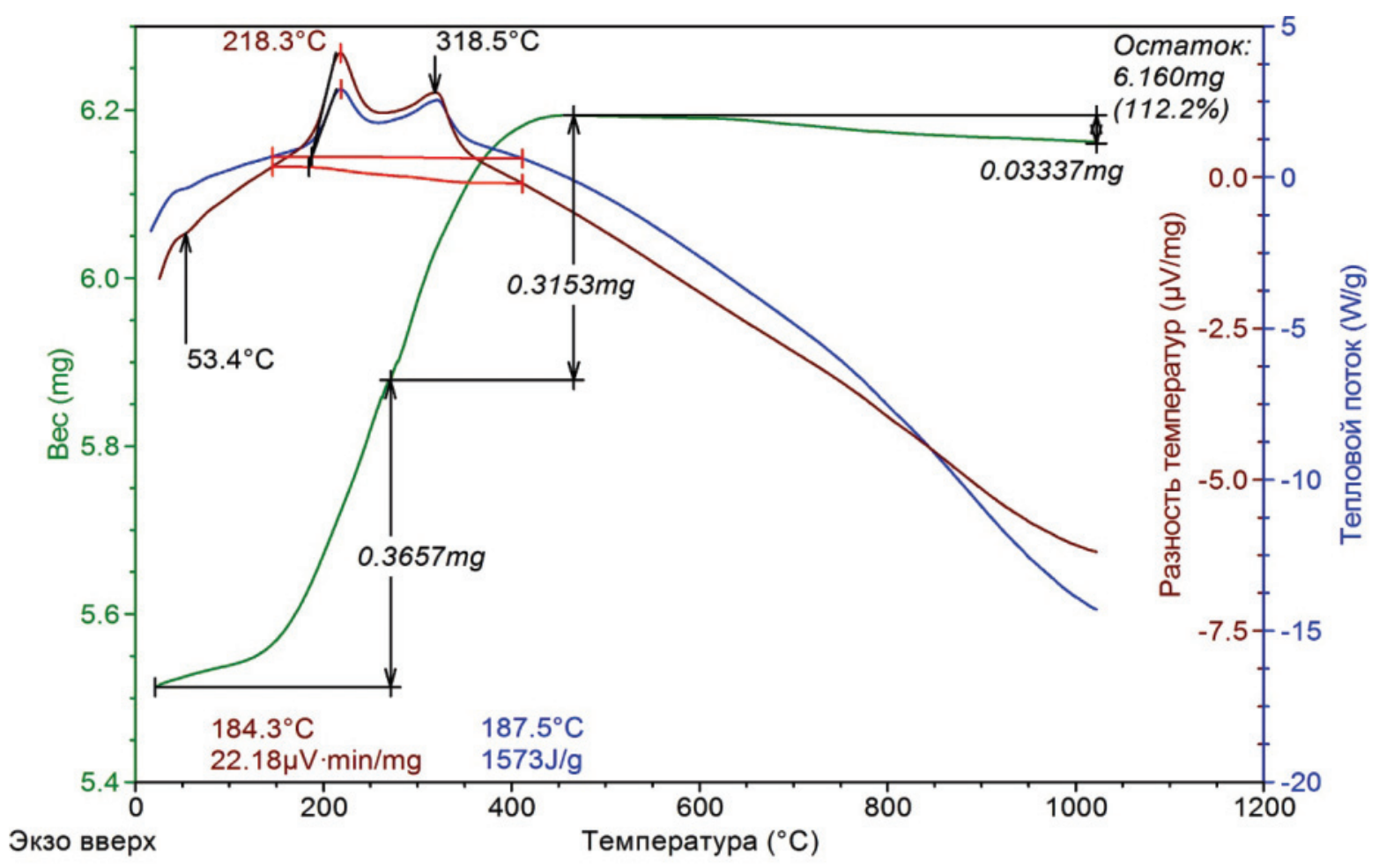

Pис. 2. Термограмла нанопорошка меди (образеи Си-26) после 16 лет хранения: масса образиа 5,4920 мг, скорость нагрева $10^{\circ}$ /лин, атмосфера - воздуx

Fig. 2. Thermogram of copper nanopowder (sample Cu-26) after 16 years of storage: sample weight is $5,4920 \mathrm{mg}$, heating rate $10^{\circ} / \mathrm{min}$, atmosphere-air

таблица 4. Относительная интенсивность 100\%-х рефлексов Си (совпадение с PDF-2, 04-0836) и СиО (совпадение c PDF-2, 01-1117) по данным рентгенофазового ана лиза после 16 лет хранения (\%)

Table 4. Relative intensity of $100 \%$ Cu reflexes (coincidence with PDF-2, 04-0836) and $\mathrm{CuO}$ (coincidence with PDF-2, 01-1117) according to $X$-ray phase analysis after 16 years of storage (\%)

\begin{tabular}{|c|c|c|c|}
\hline \multirow{2}{*}{$\begin{array}{c}\text { № образца } \\
\text { Sample no. }\end{array}$} & \multicolumn{3}{|}{$\begin{array}{r}\text { Межплоскостные расстояния, соответствующие } \\
\text { максимальным по интенсивности рефлексам }\end{array}$} \\
\cline { 2 - 4 } & $\mathrm{Cu}, d=2,1 \AA$ & $\mathrm{Cu0}, d=2,51 \AA$ & $\mathrm{Cu0}, d=2,31 \AA$ \\
\hline $\mathrm{Cu}-30$ & 100 & 11 & 10 \\
\hline $\mathrm{Cu}-28$ & 100 & 11 & 9 \\
\hline $\mathrm{Cu}-26$ & 100 & 12 & 10 \\
\hline $\mathrm{Cu}-24$ & 100 & 14 & 13 \\
\hline $\mathrm{Cu}-22$ & 100 & 10 & 9 \\
\hline $\mathrm{Cu}-20$ & 100 & 6 & 6 \\
\hline $\mathrm{Cu}-18$ & 100 & 6 & 0 \\
\hline $\mathrm{Cu}$ ПМС & 100 & 0 & 5 \\
\hline
\end{tabular}

При нагревании такой меди даже до $200{ }^{\circ} \mathrm{C}$ на поверхности формируется смесь $\mathrm{Cu}_{2} \mathrm{O}$ и $\mathrm{CuO}$. При сгорании меди в массивном состоянии в атмосфере воздуха она переходит в $\mathrm{CuO}$. Для наночастиц меди характерно образование $\mathrm{CuO}$ при пассивировании и длительном хранении (табл. 4). Этот экспериментальный результат объясняется повышенной реакционной способностью атомов меди на поверхности наночастиц, связанной с высокой кривизной поверхности $[6,7]$.

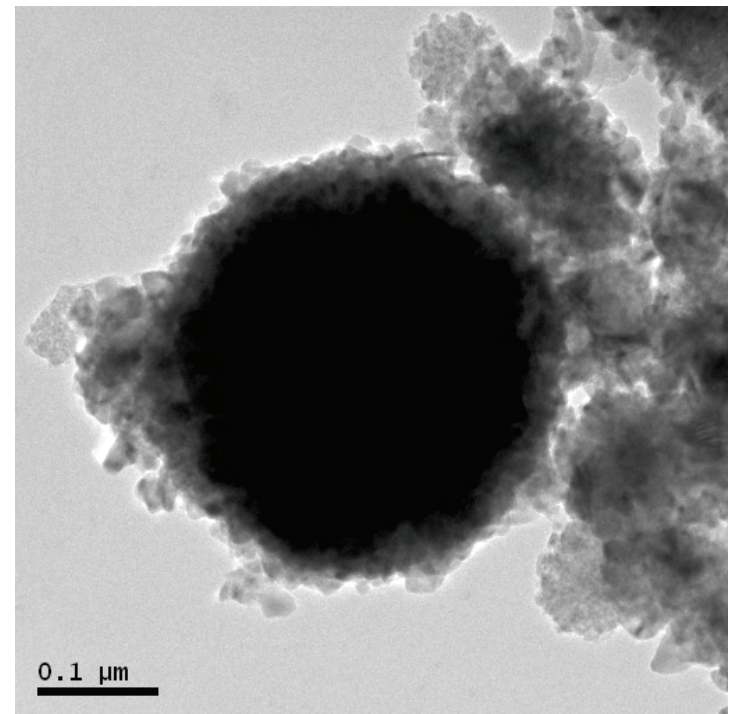

Pис.3. Микрофотография наночастии и частищы меди диаметром 300 нм после пассивирования в воздухе

Fig. 3. Micrograph of nanoparticles and copper particles with a diameter of $\sim 300 \mathrm{~nm}$ after passivation in air

На рис. 3 видно, что оксидный слой состоит из кластеров размером 4-6 нм, отделенных друг от друга поверхностью раздела, что облегчает доступ окислителей к поверхности металлической меди. K тому же кроме оксида $\mathrm{CuO}$, кристаллизующегося в моноклинной решетке $(a=0,46837 \mathrm{Hм}$, 
$b=0,34226$ нм, $c=0,51288$ нм) [19], не исключена возможность образования рентгеноаморфного оксида $\mathrm{Cu}_{2} \mathrm{O}$, вероятность образования которого термодинамически разрешена.

\section{Заключение}

Согласно результатам термического анализа исходных НПМ (табл. 2) с повышением напряжения (энергии) на взрывающемся проводнике с 18 до 30 кВ площадь удельной поверхности проходит через максимум, равный 10,2 $\pm 0,3 \mathrm{~m}^{2} /$ г. Этому же образцу соответствует приведённый тепловой эффект, равный 1,6 отн. ед. Для серии образцов НПМ температура начала окисления в пределах погрешности дериватографа постоянна: $160 \pm 5{ }^{\circ} \mathrm{C}$, т. е. не зависит от дисперсности $\left(S_{\text {уд }}\right)$. Такая ситуа-

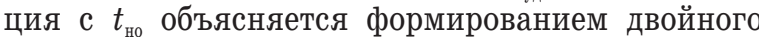
электрического слоя на поверхности наночастиц меди $[3,11,12]$. В отличие от двойного электрического слоя в коллоидной химии на наночастицах меди двойной электрический слой формируется необратимо, т. е. в результате химической реакции разложения адсорбированной воды. Образующиеся протоны, способные к диффузии, проникают внутрь наночастицы, образуя положительно заряженный предвнешний слой. Оставшиеся на поверхности гидроксид-ионы образуют отрицательно заряженный внешний слой. Толщина двойного электрического слоя по данным электронной микроскопии составляет 2-10 нм [2, 3]. После хранения НПМ в течение 16 лет в условно герметичной таре (табл. 3) наиболее заметно для образцов изменилась $t_{\text {но }}: 2$ образца стали пирофорными и содержание металлической меди в образце $\mathrm{Cu}-24$ осталось 46,7 мас. $\%$, а в образце $\mathrm{Cu}-28-47,0$ мас. $\%$. В процессе хранения в двойном электрическом слое процессы переноса заряда и массопереноса, по-видимому, не прекращаются.

\section{СПИСОК ЛИТЕРАТУРЫ}

1. Химическая энциклопедия / под ред. И.Л. Кнунянца. - М.: Изд-во «Советская энциклопедия», 1992. - Т. 3. - 639 с.

2. Effects of main particle diameter on improving particle flowability for compressed packing fraction in a smaller particle admixing system / M. Yoshida, A. Misumi, J. Oshitani, K. Gotoh, A. Shimosaka, Y. Shirakawa // Advanced Powder Technology. 2017. - V. 28. - P. 2542-2548.

3. Евстифеева Е.Н., Новикова А.А. Получение наночастиц меди термическим разложением комплекса формиата меди с триэтиламином // Международный журнал прикладных и фундаментальных исследований. - 2017. - № 3. - С. 135-139.

4. Гусев А.И. Наноматериалы, наноструктуры, нанотехнологии. - М.: Физматгиз, 2005. - 416 с.

5. Wang L., Hu C., Shao L. The antimicrobial activity of nanoparticles: present situation and prospects for the future // Int J Nanomedicine. - 2017. - № 12. - P. 1227-1249.

6. Qi W.H., Wang M.P. Size and shape dependent lattice parameters of metallic nanoparticles // J. Nanopart. Res. - 2005. - V. 7. № 1. - P. 51-57.

7. The thermal stability of high-energy ball-milled nanostructured $\mathrm{Cu} /$ J.M. Tao, X.K. Zhu, R.O. Seatlergood, C.C. Koch // Materrials and Design. -2012 . - V. 49. - № 9. - P. 22-26.
Проведённые исследования, таким образом, дают основания утверждать, что термическая устойчивость нанодисперсных порошков меди в значительной степени зависит от их структурно-энергетического состояния больше, чем от дисперсности (табл. 1,2$)$. Численные величины параметров активности не коррелируют с условиями их получения (табл. 1,2$)$, но остаются индивидуальными для каждого нанопорошка. Нанопорошки и наночастицы с двойным электрическим слоем $[3,8,9]$, согласно экспериментальным результатам по длительному хранению, следует отнести к нестабильным системам. Поэтому при демонстрации свойств нанопорошков меди необходимо указывать время их хранения, условия хранения, и это время следует ввести в систему параметров активности в качестве пятого параметра $(\tau)$. Ранее опубликованные результаты экспериментов по свойствам нанопорошков металлов необходимо оценивать критически [4-7, 20, 21], т. к. в них отсутствуют данные по времени хранения.

\section{Выводы}

1. Неустойчивость нанопорошков меди при хранении приводит к появлению их пирофорности в воздухе.

2. Устойчивость нанопорошков меди после 16 лет хранении в условно-герметичной таре не имеет определенной зависимости от относительных величин введенной энергии в проводник $\left(W / W_{\mathrm{s}}\right)$ и энергии дуговой стадии $\left(W_{\mathrm{t}} / W_{\mathrm{s}}\right)$.

3. Причина низкой термической устойчивости связана с формированием, на поверхности частиц оксида $\mathrm{CuO}$, кристаллизующегося в виде кластеров (4-6 нм), которые не образуют сплошной плёнки и не защищают медь от окисления.

Работа выполнена при финансовой поддержке Министерства науки и высшего образования РФ, проект № 11.1928.2017/4.6.

8. Hauffe K. Oxydation von Metallen und Metallegierunger. - Berlin: Springer, 1957. - $329 \mathrm{~S}$.

9. Ильин А.П., Трушина Л.Ф., Родкевич Н.Г. Электрохимические свойства электровзрывных энергонасыщенных порошков меди и серебра // Физика и химия обработки материалов. 1995. - № 3. - C. 122-125.

10. Connection between nanostructured materials' size-dependent melting and thermodynamic properties of bulk materials / W. Luo, K. Su, K. Li, Q. Li // Solid State Commun. - 2011. V. 151. - № 3. - P. 229-233.

11. Dreizin E.L. On the Mechanism of Asymmetric Aluminum Particle Combustion // Combustion and Flame. - 1999. - V. 117. № 4. - P. 841-850.

12. Пороговые явления в нанопорошках / А.П. Ильин, Л.0. Толбанова (Роот), В.В. Ан, Д.В. Тихонов // Изв. Вузов. - 2006. № 8. - C. 550-552.

13. Bennet F.D. High-temperature Exploding Wires // Progress in High-temperature Physics and Chemistry. - N.Y.: Pergamon Press, 1968. - V. 2. - 463 p.

14. Осциллографическое определение энергии электрического взрыва проволочек / И.Ф. Кварцхава, В.В. Бондаренко, А.А. Плютто, А.А. Чернов // ЖЭТФ. - 1956. - Т. 31. - № 5. - С. 745-751.

15. Искольдский А.М., Пикус В.К., Эпельбаум Я.Г. Электрический взрыв проводников. Устойчивость фронта фазового пре- 
вращения. Препринт № 32 ИА и ЭТСО АН СССР. - Новосибирск: ИА и Э, 1976. - 42 с.

16. Gleiter H. Nanostructured materials: basic concepts and microstructure // Acta mater. - 2000. - V. 48. - P. 1-29.

17. Characterization of Aluminium Powders. Parameters of Reactivity of Aluminum Powders / A.P. Ilyin, A.A. Gromov, V.V. An, F. Faubert et al. //Propellants, Explosives, Pyrotechnics. 2002. - V. 27. - № 6. - P. 361-364.

18. Уэндландт У. Термические методы анализа / пер. с англ. под ред. В.А. Степанова, В.А. Берштейна. - М.: Мир, 1978. - 526 с.

19. Химическая энциклопедия / под ред. И.Л. Кнунянца. - М.: Изд-во «Советская энциклопедия», 1990. - Т. 2. - 783 с.
20. Rezaei P., Rezaei M., Meshkani F..Low temperature CO oxidation over mesoporous iron and copper mixed oxides nanopowders synthesized by a simple one-pot solid-state method // Process Safety and Environmental Protection. - 2018. - № 119. P. 379-388.

21. Биологические эффекты воздействия свежеприготовленных и суточных водных дисперсий наночастиц меди и оксида меди на бактерии E. coli / О.В. Захарова, А.А. Гусев, Ю.В. Антибоева, С.Ю. Перова // Российские нанотехнологии. - 2018. - Т. 13. № 3-4. - C. 745-751.

Поступила 24.10.2018 г.

\section{Информация об авторах}

Tихонов Д.В., кандидат технических наук, доцент отделения электроэнергетики и электротехники Инженерной школы энергетики Национального исследовательского Томского политехнического университета.

Ильин А.П., доктор физико-математических наук, профессор отделения естественных наук Школы базового инженерного образования Национального исследовательского Томского политехнического университета.

Беспалова $\boldsymbol{E} . \boldsymbol{A}$., студентка Бийского технологического института. 
UDC 546.561

\title{
ACTIVITY PARAMETERS OF COPPER NANOPOWDER AFTER LONG STORAGE IN CONDITIONAL-HERMETIC PACKAGE
}

\author{
Dmitriy V. Tikhonov', \\ dv_1@mail.ru \\ Alexander P. Ilyin', \\ ilyin@tpu.ru

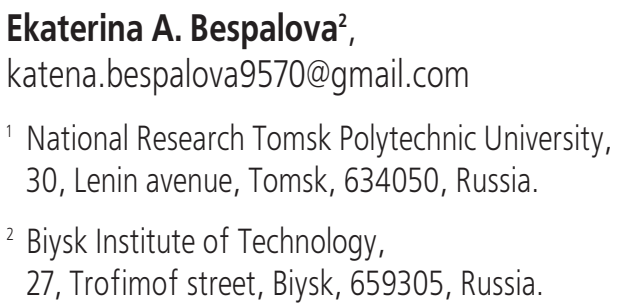

Relevance of the research is related to determination of parameters of copper nanopowders series activity after 16 years storage in an air-tight container.

The main aim of the research is to determine by the experiment four parameters of chemical activity of copper nanopowders series and to establish the laws of change in these parameters after long storage of these nanopowders in the air-tight container.

Object: copper nanopowders, produced by wire explosion technique in argon atmosphere.

Methods. Phase content of copper nanopowders series was determined "Shimadzu» XRD-700 difractometer. Sizes and shapes of nanoparticles were investigated by reflection electron microscopy JSM-750FA Jeol. Specific surface areas of nanopowders were determined by means of low temperature nitrogen adsorption (BET). Metal copper content was determined by thermogravimetry after heating up to $1250^{\circ} \mathrm{C}$ with heating speed $10^{\circ} \mathrm{min}$. Activity of copper nanopowders was characterized by four parameters of activity.

Results. After storage (16 years) of copper nanopowders in the air-tight container, some samples became pyrophoric: their oxidation temperature dropped to 19 and $16^{\circ} \mathrm{C}$. At the same time, there are samples with oxidation start temperature of 188 and $190^{\circ} \mathrm{C}$. Maximum oxidation rate of copper nanopowders was $32,3 \cdot 10^{-4} \mathrm{mg} / \mathrm{s}$, and the minimum only $5,2 \cdot 10^{-4} \mathrm{mg} / \mathrm{s}$. When copper nanopowders are heated to $650^{\circ} \mathrm{C}$, the enthalpy of their oxidation for the most part of the samples is $\approx 1500 \mathrm{~kJ} / \mathrm{mol}$. The content of metallic copper in nanopowders of the samples ranged from 46,7 to $73,5 \mathrm{wt}$. \%. The absence of correlation dependencies between the conditions of electric explosion and the parameters of activity is apparently related to the multiparameter dependence of an oxide shell formation on copper particles: the conditions of passivation are significant. A feature of copper nanopowders is the impossibility of forming a protective film on the particle surface: oxidation product is crystalline $\mathrm{CuO}$ phase and roentgenomorphic $\mathrm{Cu}_{2} \mathrm{O}$ phase in the form of $4-6 \mathrm{~nm}$ clusters.

\section{Key words:}

Nanopowder, copper, electrical explosion, parameters of activity, thermal effect, oxidation start temperature, storage, air, maximum oxidation rate, enthalpy of oxidation.

This work was financially supported by The Ministry of Education and Science of the Russian Federation, Project no. 11.1928.2017/4.6. The experimental part was carried out at Tomsk Polytechnic University within the framework of Tomsk Polytechnic University Competitiveness Enhancement Program grant.

\section{REFERENCES}

1. Khimicheskaya entsiklopediya [Chemical encyclopedia]. Ed by I.L. Knunyants. Moscow, Sovetskaya entsiklopediya Publ., 1992. Vol. 3, $639 \mathrm{p}$.

2. Yoshida M., Misumi A., Oshitani J., Gotoh K., Shimosaka A., Shirakawa Y. Effects of main particle diameter on improving particle flowability for compressed packing fraction in a smaller particle admixing system. Advanced Powder Technology, 2017, vol. 28 , pp. 2542-2548.

3. Evstifeeva E.N., Novikova A.A. Production of copper nanoparticles by thermal decomposition of a complex of copper format with trimethylamine. International Journal of Applied and Fundamental Research, 2017, no. 3, pp. 135-139. In Rus.

4. Gusev A.I. Nanomaterialy, nanostruktury, nanotekhnologii [Nanomaterials, nanostructures, nanotechnologies]. Moscow, Fizmatgiz Publ., 2005. 416 p.

5. Wang L., Hu C., Shao L. The antimicrobial activity of nanoparticles: present situation and prospects for the future. Int J Nanomedicine, 2017, no. 12, pp. 1227-1249.
6. Qi W.H., Wang M. P. Size and shape dependent lattice parameters of metallic nanoparticles. J. Nanopart. Res., 2005, vol. 7, no. 1 , pp. 51-57.

7. Tao J.M., Zhu X.K., Seatlergood R.0., Koch C.C. The thermal stability of high-energy ball-milled nanostructured $\mathrm{Cu}$. Materrials and Design, 2012, vol. 49, no. 9, pp. 22-26.

8. Hauffe K. Oxydation von Metallen und Metallegierunger [Metal oxidation]. Berlin, Springer, 1957. 390 p.

9. Ilin A.P., Trushina L.F., Rodkevich N.G. Electrochemical properties of electric blasting energy-saturated powders of copper and silver. Physics and Chemistry of Materials Processing, 1995, no. 1, pp. 122-125. In Rus.

10. Luo W., Su K., Li K., Li Q. Connection between nanostructured materials' size-dependent melting and thermodynamic properties of bulk materials. Solid State Commun., 2011, vol. 151, no. 3, pp. 229-233.

11. Dreizin E.L. On the Mechanism of Asymmetric Aluminum Particle Combustion. Combustion and Flame, 1999, vol. 117, no. 4, pp. 841-850. 
12. Ilin A.P., Tolbanova (Root) L.0., An V.V., Tihonov D.V. Threshold phenomena in nanopowders. Bulletin of the higher educational institutions, 2006, no. 8, pp. 550-552. In Rus.

13. Bennet F.D. High-temperature Exploding Wires. Progress in High-temperature Physics and Chemistry. N.Y., Pergamon Press, 1968. Vol. 2, $463 \mathrm{p}$.

14. Kvartskhava I.F., Bondarenko V.V., Plyutto A.A., Chernov A.A. Oscillographic determination of electrical explosion energy of wires. Journal of Experimental and Theoretical Physics, 1956, vol. 31, no. 5, pp. 745-751. In Rus.

15. Iskoldsky A.M., Pikus V.K., Epelbaum Ya.G. Elektrichesky vzryv provodnikov. Ustoychivost fronta fazovogo prevrashcheniya [Electric explosion of conductors. Stability of the phase transformation front]. Novosibirsk, IA i EH Publ., 1976. 42 p.

16. Gleiter H. Nanostructured materials: basic concepts and microstructure. Acta mater., 2000, vol. 48, pp. 1-29.

17. Ilyin A.P., Gromov A.A., An V.V., Faubert F. Characterization of Aluminium Powders. T. Parameters of Reactivity of Aluminum
Powders. Propellants, Explosives, Pyrotechnics, 2002, vol. 27, no. 6 , pp. 361-364.

18. Uehndlandt U. Termicheskie metody analiza [Thermal Methods of Analysis]. Translated from English. Eds. V.A. Stepanova, V.A. Bershteyna. Moscow, Mir Publ., 1978. 526 p.

19. Khimicheskaya entsiklopediya [Chemical encyclopedia]. Ed. by I.L. Knunyants. Moscow, Sovetskaya entsiklopediya Publ., 1990. Vol. 2, $783 \mathrm{p}$.

20. Rezaei P., Rezaei M., Meshkani F. Low temperature C0 oxidation over mesoporous iron and copper mixed oxides nanopowders synthesized by a simple one-pot solid-state method. Process Safety and Environmental Protection, 2018, no. 119, pp. 379-388.

21. Zaharova 0.V., Gusev A.A., Antiboeva Yu.V., Perova S.Yu. Biological effects of freshly prepared and daily water dispersions of copper nanoparticles and copper oxide on E. coli bacteria. Russian nanotechnology, 2018, vol. 13, no. 3-4, pp. 745-751. In Rus.

Received: 24 October 2018.

\section{Information about the authors}

Dmitriy V. Tikhonov, Cand. Sc., associate professor, National Research Tomsk Polytechnic University.

Alexander P. Ilyin, Dr. Sc., professor, National Research Tomsk Polytechnic University.

Ekaterina A. Bespalova, student, Biysk Institute of Technology. 